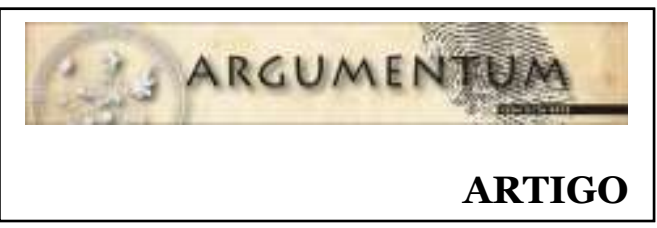

\title{
A gravidade do neoliberalismo radical pós 2008 e nossas estratégias de resistência
}

\author{
The threat of radical neoliberalism after 2008 and our strategies for resistance
}

\author{
Eduardo Mourão VASCONCELOS*
}

https://orcid.org/oooo-0002-3490-3596

\section{Introdução}

A

o receber o convite para este texto provocador da seção debates da Revista Argumentum, que tem neste volume como tema central as políticas de saúde mental no Brasil e no plano internacional: tendências e desafios, decidi tomar a liberdade de retomar aqui o argumento central de meu livro publicado em 2016 ("Reforma psiquiátrica, tempos sombrios e resistência" [VASCONCELOS, 2016]), e propor um foco um pouco mais ampliado para esta discussão. Naquela obra, mais como cientista político do que psicólogo, procurei desenvolver algumas hipóteses. Em primeiro lugar, de que o movimento antimanicomial e seus principais representantes teóricos vêm apresentando uma tendência de pensar a política de saúde mental em si mesma, de forma isolada da conjuntura histórica mais ampla e das demais políticas sociais, e têm mobilizado seus militantes para a luta, durante as últimas décadas, tendo como mote principal a interpelação de sua implicação pessoal e profissional com o processo de reforma psiquiátrica e com o movimento antimanicomial. Podemos traduzir isso nas seguintes expressões frequentes: vamos segurar a reforma psiquiátrica à unha, ou ...com o nosso próprio corpo . Em segundo lugar, esse tipo de interpelação, no atual contexto de deterioração das condições de trabalho na rede de saúde e saúde mental, tem levado nossos trabalhadores de saúde e saúde mental a três consequências preocupantes: (a) esgotamento (burn out) (SELIGMANN-SILVA, 2011), ou segundo outros autores, também à fadiga por compaixão (LAGO; CODO, 2010); (b) a práticas burocráticas e defensivas, tendentes ao encaminhamento não responsável ou a atendimentos frios e insensíveis; ou (c) a simplesmente abandonar o campo da saúde mental. Assim, o livro convida os leitores para se capacitarem para uma análise mais cuidadosa da conjuntura econômica, política e social, no sentido de compreender os 'sinais da história'; de planejar melhor os recuos quando são necessários ou inevitáveis;

\footnotetext{
* Psicólogo e Cientista político. Doutor pela London School of Economics and Political Science. Professor aposentado da Universidade Federal do Rio de Janeiro. (UFRJ, Rio de Janeiro, Brasil). Militante dos movimentos de reforma psiquiátrica e luta antimanicomial no Brasil. E-mail: emvasconcelos56@gmail.com.
} 
de identificar as pequenas brechas para práticas inovadoras, que serão fundamentais em conjuntura mais favoráveis no futuro; e fundamentalmente, para desenvolver uma visada mais alongada para a história humana, capaz de nos induzir a necessária paciência histórica para poder resistir e continuar lutando durante este período sombrio, que dá sinais claros de que não será curto. Assim, neste texto de abertura de debate, quero retomar estas hipóteses e aprofundá-las ainda mais, no sentido de pensar a atual crise da política de saúde mental no contexto das tendências emergentes da conjuntura histórica, que na minha opinião está mostrando mudanças qualitativas profundas, para as quais considero que nós, da esquerda brasileira formada nas lutas sociais e políticas das décadas de 1970 a 2000, estamos despreparados e desorientados.

Assim, se quisermos discutir e traçar estratégias de resistência e luta com maior efetividade, tema a ser retomado brevemente no final deste ensaio, temos que ampliar nosso enquadramento e análise da conjuntura mundial e brasileira, reconhecendo o caráter global e multidimensional do projeto histórico neoliberal em sua versão mais radical, gerador de uma crise civilizatória que aponta para a barbárie, mesmo que isso, num primeiro momento, possa nos parecer longe demais de nossa realidade, ou desanimador e pessimista demais.

Em outras palavras, pretendo desenvolver neste ensaio a hipótese de que a atual crise das políticas sociais e de saúde mental no Brasil e no mundo tem raízes muito mais profundas do que imaginamos, em um projeto histórico operado a meu ver por um novo ciclo qualitativamente diferenciado das políticas neoliberais a nível mundial. No Brasil, nós, da esquerda, estamos desorientados com as características similares ao fascismo que esse ciclo apresenta. Alguns de nossos companheiros de luta, muitas vezes sem grande esforço de análise, ficam mais na indignação, como se nosso governo estivesse sido apropriado apenas por um grupo de políticos do tipo baixo clero, de orientação fascista, orientado por um guru amalucado como o Olavo de Carvalho. Em um nível mais aprofundado, boa parte de nossas análises e ações são marcadas pela denúncia de retrocessos nos direitos políticos e sociais, e de como eles retomam as raízes da política e da cultura da ditadura civil-militar, ou ainda determinantes mais antigos, de nosso passado colonial, escravista, patriarcal e homofóbico, dimensões que não foram devidamente elaboradas e superadas no período da pós-redemocratização. Isso é em parte real e correto, mas tendemos a esquecer que o fenômeno é também mundial, que atinge inúmeros países até mesmo de forte tradição liberal ou social democrata, seja tendo seus movimentos sociais e partidos de ultradireita ou neonazistas assumindo diretamente o governo, seja tendo crescimento de forma assustadora em seus parlamentos, como indicado mais abaixo. Em suma, o atual flash back de retomada dos componentes políticos, sociais e culturais mais sombrios da história brasileira não é aleatório, é interpelado por forças econômicas, políticas e sociais mais amplas e poderosas a nível mundial. E além disso, tem várias dimensões orgânicas, muitas das quais progressivas, sejam ambientais, tecnológicas e informacionais, com fortes repercussões na questão social e na organização do trabalho, na troca diária de mensagens e dados pelas pessoas comuns, e também nos processos de subjetivação de cada um de nós, e que atingem em cheio os padrões até então reconhecidos da vida e dos valores políticos, morais e éticos. Ou seja, não estaremos aqui considerando apenas os processos econômicos e políticos estruturais, como nas análises marxistas mais

Argum., Vitória, v. 12, n. 2, p. 47-66, maio/ago. 2020. | ISSN 2176-9575 
convencionais, mas também aspectos da cultura política e dos processos de subjetivação, bem como acontecimentos históricos singulares que contribuíram para aprofundar essas tendências.

Diante de contextos históricos como este, gostaria de lembrar da interpelação de Gramsci sobre a necessidade do pessimismo da razão e do otimismo da prática. Contudo, proponho matizá-la com uma distinção que considero importante, sobre a natureza do discurso que utilizo aqui. A partir de uma diferenciação entre diferentes tipos de discurso, que sistematizei em um de meus volumes sobre Karl Marx e a subjetividade humana (VASCONCELOS, 2010), penso que os argumentos que pretendo desenvolver aqui se encaixam mais claramente no discurso do tipo acadêmico, voltado para um público com maior capacidade reflexiva e de reconhecer mais abertamente as agruras e contradições profundas da história humana. Como sou também um militante antimanicomial, muito vezes convidado a falar para grupos e coletivos de militantes trabalhadores, usuários de serviços e seus familiares, utilizo nestas ocasiões um discurso mais diretamente político que, embora sempre sustentado academicamente, tende a se focar mais nas mediações, contradições e brechas em um plano político mais imediato e microsocial, e mais especificamente dentro do campo da saúde mental, visando fundamentalmente gerar esperança de um futuro melhor e mobilizar para as lutas possíveis do momento. O presente ensaio visa mostrar desafios profundos, complexos, polêmicos, para muitos dos quais penso que ainda não temos uma reflexão mais sistemática, e nem mesmo estratégias claras de como enfrentá-los. Assim, considero que o presente ensaio constitui uma provocação e um convite a nossos colegas principalmente da esfera acadêmica, mas também a lideranças políticas, para se debruçarem sobre eles, para podermos avançar na compreensão do momento mais global em que vivemos, reconhecendo uma relativa inevitabilidade histórica de alguns retrocessos, como subsídio de fundo para a discussão das estratégias teóricas, e práticas de nossas lutas mais gerais do campo da esquerda e da saúde mental. Assim, não teremos condições de tratar aqui das mediações diretas com as políticas sociais e de saúde mental na esfera nacional, estadual e municipal, que possibilitam identificar mais concretamente as brechas para lutas e resistência, embora haja rápidas indicações disso no final, no sentido de mostrar a necessidade e a possibilidade dessa resistência.

\section{A caracterização mais conhecida das principais ideias e políticas neoliberais}

As teorias neoliberais tiveram suas formulações iniciais a partir do final da década de 1930, particularmente no colóquio de Lippman, em 1938, em Paris, propondo reduzir radicalmente os componentes de políticas públicas de bem estar social, inspiradas nas primeiras experiências nacionais europeias a partir de 1880, no socialismo soviético e nas políticas de New Deal nos Estados Unidos, após a crise de 1929, sistematizadas principalmente por Keynes (1883-1946) e seguidores. A partir daí, os principais teóricos neoliberais, tais como Hayek (1899-1992), da Escola Austríaca, e Friedman (1912-2006), da Escola de Chicago, defenderam de forma mais sistemática políticas de austeridade fiscal, redução da esfera e das ações estatais, privatização das propriedades e dos serviços públicos, controle dos sindicatos dos trabalhadores, desregulamentação dos fluxos de capital, e impostos e tarifas favoráveis ao grande capital, suprimindo seus aspectos redistributivos. Estas ideias ficaram praticamente restritas ao ambiente acadêmico 
durante o ciclo keynesiano de desenvolvimento dos chamados estados de bem estar social, mais fortemente assentados em países europeus, até a década de 1970, quando foram aplicadas inicialmente na ditadura chilena liderada por Pinochet, assessorado pelos economistas formados na Escola de Chicago (que incluía o nosso atual ministro da Economia, Paulo Guedes). Várias destas políticas foram impostas aos demais países de Terceiro Mundo, particularmente pelo Fundo Monetário Internacional, como exigências para a aceitação de pacotes de ajuda financeira. Na virada dos anos 1970-8o, os governos de Margareth Thatcher, na Inglaterra, e Ronald Reagan, nos EUA, iniciaram sua implementação em seus respectivos países, difundindo-as assim para os demais países desenvolvidos, bem como atingindo em cheio, a partir do final da década de 1980, os países até então reunidos na União Soviética, que passaram então por uma transição rapidíssima e violenta de um socialismo burocrático e de estatismo extremo, para uma gestão inteiramente neoliberal da economia e das políticas públicas.

No plano internacional, a figura do Estado-Nação com relativa autonomia e soberania para realizar pactos sociais, mediante políticas sociais, e para manter a demanda agregada da economia interna, inspiradas na abordagem keynesiana, foi gradualmente desconstruída, em favor da livre circulação de mercadorias e de capitais, perspectiva fomentada pelas agências internacionais. A emergência econômica da China e mais tarde de outros países populosos ou com amplo exército de reserva, como a Índia, com taxas altas de crescimento econômico e políticas internas de ausência quase total de direitos trabalhistas e previdenciários, estimulou a colocação de seus produtos baratos no mercado mundial, estimulando ainda mais os ideais neoliberais de nivelamento por baixo dos salários, perda substantiva de direitos do trabalho e de deslocamento de unidades de produção industrial e de serviços para estes países, fomentando um processo de desindustrizalização em inúmeros outros países, desenvolvidos ou não. Esse processo, somado à introdução da informática e robótica nas linhas de produção, aumentou ainda mais as taxas de desemprego, de desempregados que não procuram trabalho (desalento), e o mercado informal de trabalho.

Estas mudanças na esfera mais diretamente econômica foram acompanhadas de profundas transformações ideológicas, culturais e subjetivas, deslocando o cidadão com demandas econômicas e sociais, muitas delas coletivas, forçando-o a se moldar ao status de um sujeito fortemente individualizado, competitivo, portador de capital humano, flexível, estimulado a ter múltiplas aptidões e competências operativas e organizacionais, com forte acento no empreendedorismo pessoal, ethos embalado por um crescimento vertiginoso da literatura de auto ajuda. $\mathrm{Na}$ base mais pobre da sociedade, temos um aumento vertiginoso do desemprego estrutural, fomentado também pela automatização crescente do processo de trabalho na indústria e nos serviços, transformando parcelas cada vez maiores da população economicamente ativa em população sobrante, deslocando-a para o mercado informal de trabalho ou simplesmente sem qualquer possibilidade de ser inserida economicamente e de gerar renda para si e sua família.

Essas mudanças exigiram, por sua vez, novas formas de gestão de governo, que transportam a racionalidade de livre regulação do mercado para as agências de governo, e governos reformatados para servir os mercados, que por sua vez, também realimentam 
os valores, ideologias e culturas neoliberais a serem difundidas na vida social como um todo.

Além disso, um dos efeitos colaterais adicionais mais drásticos de todas estas transformações na esfera mundial foi, sem dúvida alguma, a perda da regulação sobre os efeitos ambientais do crescimento econômico, e particularmente sobre o aquecimento global, pela destruição das florestas e áreas verdes e uso intensivo de combustíveis fósseis, que liberam carbono na atmosfera, acentuando o efeito estufa. Isso tem gerado aumento gradual da temperatura no planeta, degelo nos polos e nas cadeias de montanhas mais altas, aumentando o nível dos oceanos, com enorme risco para inúmeras espécies vivendo nos mares e continentes, aumento da frequência e periculosidade de eventos climáticos radicais (secas, incêndios florestais, enchentes, tempestades, furacões etc) e diminuição acentuada da oferta de água doce e potável no planeta, o que aponta para o acirramento de conflitos e guerras pelo acesso a água.

Durante a década de 2000 , dado o ritmo acelerado da economia chinesa e mundial, e a forte demanda por comodities produzidas por países periféricos, o Brasil e alguns outros países latino-americanos tiveram a possibilidade de um pequeno avanço relativo em termos de conquistas sociais. A conjuntura econômica mundial favorável foi capitalizada politicamente por partidos de centro-esquerda e esquerda, o que possibilitou alguns avanços na distribuição de renda e nas políticas sociais, em países como Brasil (gov. Lula), Argentina, Uruguai, Equador, Bolívia, Venezuela e Nicarágua. Este pequeno intervalo é interrompido a partir de 2008 , com a crise e recessão internacional gerada pela irresponsável bolha imobiliária e financeira nos EUA, processo que se expandiu para todo o mundo capitalista, atingindo também os países centrais, e neles, particularmente os países da União Europeia um pouco mais frágeis do ponto de vista econômico, tais como a Irlanda, Portugal, Espanha, Itália e Grécia. No Brasil, as políticas anticrise implementadas a partir de 2008, no segundo governo Lula, e no primeiro governo Dilma, até 2013, conseguiram atrasar a chegada desta crise no Brasil, mas depois desse ano, a crise aberta na economia foi inevitável, gerando ou contribuindo também para uma crise política profunda.

\section{As estratégias de desmonte do social, do político e da democracia dos intelectuais neoliberais, e sua radicalização após a crise de 2008}

Para o enquadre da hipótese de um projeto gerador de crise civilizacional e barbárie, que propus acima, gostaria de me referenciar, particularmente nos próximos trechos, em uma obra cuja leitura recomendo fortemente, Nas ruínas do neoliberalismo: a ascensão da política antidemocrática no Ocidente, de Wendy Brown (2019), professora de Ciência Política da Universidade de Berkeley, EUA, a partir do seu resgate dos debates e análises de acadêmicos de esquerda gerados pela ascensão de Trump ao poder naquele país em 2016. O livro foi publicado lá em 2019, mas teve tradução imediata e publicação neste mesmo ano também aqui no Brasil. O caráter cosmopolita desta discussão é fundamental, para nos remeter a dimensões mais globais que muitas vezes são pouco valorizadas no debate brasileiro, como indicado acima, pois as principais características da atual política brasileira foram, em primeiro lugar, explicitamente inspiradas em estratégias já desenhadas pelos intelectuais neoliberais há décadas, e foram radicalizadas 
na conjuntura mundial que se abre após a crise econômica e financeira de 2008. Para isso, é preciso revisitar brevemente as ideias chaves dos mais importantes pensadores e atores políticos neoliberais.

Para Brown, os principais intelectuais do neoliberalismo, como também seus principais atores políticos, propuseram efetivamente um ataque conceitual, normativo e prático às ideias de sociedade e de social como terreno que propicia a justiça e o bem comum. Hayek foi o formulador mais rigoroso deste ataque, sistematizando os seus "[...] fundamentos epistemológicos, ontológicos, políticos e econômicos e até mesmo morais [...]" (BROWN, 2019, p. 41), descritos em sua obra, mas impossíveis de serem reproduzidos aqui. No entanto, podemos citar aqui um breve trecho de síntese:

[...] 'Sociedade' é um termo pejorativo para a direita hoje, que denuncia os 'guerreiros da justiça social' (social justice warriors) por minar a liberdade com uma agenda tirânica de igualdade social, de direitos civis, de ação afirmativa e até mesmo de educação pública. $\mathrm{O}$ neoliberalismo tinha o franco objetivo de desmantelar o Estado social, seja privatizando-o (a revolução de ReaganThatcher), seja delegando suas tarefas (a 'Grande Sociedade' do Reino Unido e os 'mil pontos de luz' de Bush), seja eliminando completamente tudo o que resta de bem-estar social ou 'desconstruindo o Estado administrativo' (o objetivo de Steve Bannon ${ }^{1}$ para a presidência de Trump. Em cada caso, não é apenas a regulação e a redistribuição sociais que são rejeitadas como interferência inapropriada nos mercados ou como assaltos à liberdade. A dependência da democracia em relação à igualdade política também é alijada (BROWN, 2019, p. 38-39).

Para a autora, a base da nova forma de gestão dos indivíduos, e não mais do social, está na lógica orgânica e dinâmica do mercado e da moral, que unem os humanos de forma independente das ideias racionais, da coerção e da regulação/punição estatal. Nesta formulação, haveria uma desmassificação dos coletivos gerados por situações comuns, tal como o de proletarização dos trabalhadores, por meio de estratégias de empreendedorismo, responsabilização pessoal, transformação de suas habilidades em 'capital humano', reinserção na família e comunidade, e realocação de suas necessidades em práticas de autoprovisão, no cuidado dos filhos, educação, saúde, aparência e provisão para a velhice, tornando-os mais resilientes às crises e recessões econômicas. Lares urbanos com quintais poderiam produzir hortas e galinhas, e os desproletarizados e dessindicalizados poderiam entrar na economia da terceirização, transformando suas pequenas posses, qualidades e seu tempo em fontes de capitalização, arrendando seus quartos no Airbnb, trabalhando no Uber ou em aplicativos de entrega, compartilhando veículos e bicicletas (tema abordado mais à frente), ou simplesmente em 'bicos' de vários tipos. Assim, para Brown, os intelectuais neoliberais defendem o argumento de que estaria 'salvando' e resgatando o indivíduo, a família e os vínculos comunitários da 'desintegração típica' ou da 'aparente extinção' provocada pela modernidade tardia, transformando-os em capital humano, como unidades familiares ou comunitárias econômico-morais. Essa característica nos ajuda a compreender melhor a aliança que os atores políticos neoliberais têm construído com os setores religiosos evangélicos mais conservadores, que os apoiam maciçamente nos processos eleitorais e na legitimação de

\footnotetext{
${ }^{1}$ Uma explicação sobre Steve Banon está disponível mais à frente.
} 
suas gestões políticas, tema tratado em detalhe em outro trabalho de minha autoria (VASCONCELOS; CAVALCANTE, 2019).

Segundo Brown (2019), há nas formulações das teorias neoliberais um deslocamento do conceito de liberdade, que é arrancada do social, sem preocupações com as consequências sociais e com a sociedade como um todo, em seu bem comum, reduzindo-a à ausência de coerção e regulação. O conceito é então reconstruído com novos fundamentos jurídicos. A justiça se referiria apenas a princípios corretos e conhecidos por todos, aplicados universalmente, e não a resultados e efeitos, e todo jogo tem vencedores e perdedores, como no processo da evolução biológica. Isso legitimaria, portanto, em nome da 'liberdade', a privação de direitos sociais como moradia, assistência à saúde e educação.

De forma semelhante, a abordagem da esfera da política é também completamente reconceitualizada pelos intelectuais neoliberais. Brown (2019) assinala que, embora eles tenham visões diferenciadas em relação ao político, visões estas que ela examina com mais detalhe em sua obra, todos eles se opuseram ao ideal de sociedades politicamente planejadas ou reguladas, procurando conter radicalmente as formas de poder político, subordinando-os à economia e às exigências do mercado. Eles se opunham em especial às ideias de soberania popular e soberania política, como impróprias para as sociedades 'livres'. O ataque comum é principalmente contra as formas de "[...] democracia robusta - movimentos sociais, participação política direta ou demandas democráticas ao Estado - que identificaram como totalitarismo, o fascismo ou o governo da plebe" (BROWN, 2019, p. 75). Friedman e Hayek apostaram mais na organicidade das regras do mercado se expandindo para a esfera do político, enquanto os autores mais recentes e com viés ainda mais autoritário, chamados por Brown de ordoliberais, não rejeitam a soberania do Estado, apenas buscam “[...] desdemocratizar o Estado e substituí-lo por outro, suportado pela expertise técnica, dirigido por autoridades competentes e devotado aos princípios de uma economia competitiva e liberalizada" (BROWN, 2019, p. 93). E resume criticamente, dizendo que, apesar das diferenças, o efeito mais geral destas abordagens é "[...] gerar uma cultura antidemocrática desde baixo, ao mesmo tempo em que constrói e legitima formas antidemocráticas de poder estatal desde cima” (BROWN, 2019, p. 39).

No entanto, a autora reconhece que esta racionalidade neoliberal "[...] não causou a insurgência da extrema direita no Ocidente de hoje [...]" (BROWN, 2019, p. 16), mas “[...] preparou o terreno para as forças ferozmente antidemocráticas na segunda década do século XXI[...]" (BROWN, 2019, p. 16). Para isso, segundo ela, contribuíram vários processos e eventos:

- a crise econômica e financeira de 2008 e anos seguintes;

- o desenvolvimento da Internet e de uma mídia altamente setorizada e isolada, particularmente nas redes sociais;

- várias crises econômico/sociais e conflitos armados, como a guerra na Síria, a criação do Estado Islâmico e a guerra de gangues na Guatemala, gerando uma onda de refugiados e migrantes para a Europa e Estados Unidos;

- o declínio e sucateamento das políticas sociais, com efeitos arrasadores para os que vivem do trabalho (BROWN, 2019). 
A esse tópico, creio ser interessante acrescentar a difusão da automatização e a crise de desindustrialização em vários países, mesmo centrais, com aumento do desemprego e empobrecimento de vastos setores de trabalhadores e da classe média, já indicados acima.

De meu ponto de vista, é preciso ampliar um pouco mais a análise da autora. Temos experiências históricas similares ao longo do século XX, em conjunturas de profunda e continuada crise econômica e social, nas quais a burguesia liberal, defensora da democracia formal e de alguns direitos humanos, não consegue encaminhar respostas consideradas adequadas de saída da crise. Neste contexto, as forças antidemocráticas, de ultradireita ou fascistas, que se mantinham sob o manto político da direita liberal, ganham autonomia e partem para uma carreira política autônoma. Isso aconteceu após a crise gerada pela I Guerra Mundial (1914-1918) e pela crise de 1929, dando origem ao nazismo alemão e ao fascismo italiano ${ }^{2}$. A meu ver, há algumas semelhanças claras com o que estamos vivendo hoje. Para exemplificar isso, basta vasculharmos os processos eleitorais nos últimos anos, nos quais tivemos ou ainda temos vários países centrais com forças ou partidos políticos de extrema direita no poder ou participando dele: os EUA (Trump), Reino Unido (Boris Johnson), Israel, Dinamarca, Hungria, Finlândia, Áustria, Polônia, Eslovênia e Itália. Em países com tradição democrática mais sólida, como a França, Holanda e Inglaterra, bem como no Parlamento Europeu, os partidos de extrema direita tiveram um crescimento significativo nas últimas eleições de 2019. No Oriente, a Índia está sendo governada por um governo de ultradireita, com claro alinhamento a Trump e Bolsonaro, e com forte componente de discriminação legal contra os islâmicos.

Além disso, em relação ao trabalho de Brown (2019), penso que é preciso mostrar de forma mais enfática a importância das transformações profundas geradas pelas novas tecnologias digitais, e as novas forças políticas e estratégias utilizadas pela ultradireita para promover o desmonte da democracia em cada país e no nível mundial. Assim, as estratégias originalmente pensadas pelos intelectuais neoliberais passam a ser atualizadas de forma mais orgânica e com alta capacidade técnica de sistematização e adaptação para cada país, de entronização nos processos eleitorais e na vida política e difusão em todo o mundo, por meio de poderosas agências internacionais de ultradireita, do tipo Think Tanks (de elaboração de pensamento econômico e político estratégico, formação de quadros, financiamento de ações e articulação política e cultural para implementá-las), empresas de big data (capazes de processar informações em uma escala gigantesca), espionagem digital em larga escala e difusão em massa de

\footnotetext{
${ }^{2} \mathrm{O}$ conceito de fascismo é complexo e multifacetado, com variações nos países onde aconteceu, mas temos em nossa memória da história do século XX essas duas experiências marcantes: o fascismo italiano e o nazismo alemão, que mostraram um enorme potencial destrutivo, levando a maioria dos países à Segunda Guerra Mundial e ao holocausto. Para os interessados no tema, recomendo ler pelo menos o verbete Fascismo no clássico Dicionário de política, de Norberto Bobbio e outros (BOBBIO et al., 1995). Abaixo, temos algumas das características típicas do fascismo identificadas por eles, e que têm elementos similares no contexto atual:

- sistema autoritário de dominação, com base em partido e organizações de massa;

- ideologia fundada no culto de chefe ou grande líder, que pode ser oriundo de um setor específico da classe média; desprezo pela democracia liberal, e oposição frontal ao socialismo e comunismo;

- aniquilamento das oposições, incluindo o uso de violência e do terror;

- aparelho de propaganda baseado no controle das informações e meios de comunicação de massa;

- tentativa de integrar nas estruturas de controle do partido e do Estado à totalidade das relações econômicas, políticas e culturais.
} 
fake news, com efeitos ontológicos, epistemológicos e subjetivos profundos, geradores do fenômeno denominado de pós-verdade, tema da seção mais abaixo.

\section{A radicalização das mudanças na esfera do trabalho sob comando da ultradireita}

Esse tema mereceria uma vasta análise e debate, impossível neste texto, e assim só as linhas mais gerais serão indicadas. Estamos atravessando uma transição dramática e profunda, de uma sociedade industrial para uma sociedade de serviços. Para exemplificar, para o conhecido economista Marcio Pochmann, o setor industrial brasileiro representa menos de $10 \%$ do PIB, com cerca de quatro quintos dos trabalhadores concentrados no setor de serviços, com um desmoronamento do emprego clássico, pela precarização dos seus vínculos: "Eles não estão mais concentrados em grandes fábricas, mas em shopping centers, complexos hospitalares, prestando serviços para condomínios de ricos. A classe trabalhadora está cada vez mais ligada a um trabalho imaterial e submetida a nova organização temporal e espacial. Essa nova realidade não faz parte do discurso dos sindicatos e dos nossos partidos. [Nós, da esquerda] estamos com uma retórica envelhecida" (PORCHMANN apud WEISSHEIMER, 2019, não paginado).

Uma das mudanças mais significativas neste processo após a crise de 2008 tem sido o crescimento da chamada gig economy ou 'uberização' das relações de trabalho, nas quais milhares de trabalhadores autônomos prestam serviços para grandes empresas, por meio de aplicativos. A maioria de nós moradores de cidades grandes e médias no Brasil conhecem o fenômeno dos motoristas da Uber e outros aplicativos, bem como os entregadores de alimentos e encomendas em geral. No entanto, poucos de nós estão atentos às consequências sociais profundas deste processo, e para isso recomendo assistir dois filmes recentes. O primeiro é Você não estava aqui (Sorry, we missed you), em filme premiado terminado em 2018, dirigido pelo ingles Ken Loach, e recém lançado no Brasil (fevereiro de 2020), sobre um entregador de encomendas em vans e sua família, no interior da Inglaterra. O outro é um documentário brasileiro de curta metragem, intitulado Vidas entregues, de 2019, dirigido por Renato Biar, e disponível no Youtube, e que aborda a rotina de entregadores de aplicativos de comida por bicicleta na cidade do Rio de Janeiro, ganhando entre 20 a 50 reais por dia.

No entanto, é necessário qualificar melhor esse processo como um todo, no sentido de questionar a ideia de uma linearidade tecnológica inevitável e considerar também as variáveis políticas que incidem sobre ele. De acordo com a análise realizada em 2019 sobre os principais países da OCDE por Antonio Antón, professor de sociologia da Universidade Autônoma de Madri, não se trata de um desaparecimento linear do emprego, mas uma reestruturação e um crescimento em ritmo menor da população. Há sim um processo revolução tecnológica, gerando “[...] desemprego massivo, precarização do emprego, desvalorização salarial, segmentação, segregação e desequilíbrio nas relações trabalhistas [...]" (ANTÓN, 2019, não paginado), com diminuição “[...] do emprego decente e de qualidade, e se gera empobrecimento, desigualdade e incerteza" (ANTÓN, 2019, não paginado). Contudo, não se trata de um determinismo tecnológico com desaparecimento do emprego formal: nos países da OCDE, “[...] nas duas décadas entre 1995-2015, houve uma alta destruição do emprego de qualificação

Argum., Vitória, v. 12, n. 2, p. 47-66, maio/ago. 2020. | ISSN 2176-9575 
média em todos os países e uma criação nos dois extremos: significativa dos empregos muito qualificados e limitada dos menos qualificados" (ANTÓN, 2019, não paginado). Assim, no atual "[...] contexto de desigualdade, o sentido e a dimensão do impacto da revolução tecnológica no emprego depende da orientação política do poder econômicofinanceiro e institucional, da regulamentação da globalização neoliberal e das características das políticas públicas" (ANTÓN, 2019, não paginado). Em outras palavras, esse processo é altamente dependente das relações de poder político nos processos de produção, distribuição e informação, com possibilidades reais no sentido de "[...] revalorizar a importância do trabalho não mercantil e a justa divisão de toda a carga social [...]"(ANTÓN, 2019, não paginado), como também na direção de “[...] um plano de garantias de rendas sociais que busca enfrentar a vulnerabilidade social e a pobreza e fomentar a integração social, a igualdade, e a cidadania social, renovando o contrato social de reciprocidade de direito4s e deveres e a função do trabalho" (ANTÓN, 2019, não paginado).

\section{As mudanças tecnológicas digitais e suas profundas implicações epistemológicas, políticas e subjetivas, e sua apropriação atual pelas forças de ultradireita}

As novas tecnologias de computação e informação, a despeito de seus inúmeros aspectos positivos de produção coletiva de conhecimento e informação, e de sua disseminação horizontal em tempo real, acabaram gerando novas formas de poder e espionagem digital, até agora incontroláveis. As agências de espionagem da CIA e do governo dos EUA têm hackeado informações sigilosas de pessoas, autoridades, instituições e empresas estratégicas em todo o mundo, investigando a corrupção em países nos quais têm interesse em derrubar governos não aliados aos seus interesses estratégicos e econômico-financeiros, e enfraquecer empresas concorrentes com as suas. Mais tarde, Rússia e China também desenvolveram esses métodos. Para os interessados, o filme Snowden, do famoso diretor de cinema crítico norte-americano Oliver Stone, lançado em 2016, conta a história real do funcionário que vazou inúmeros dados da espionagem realizada pelas agências de segurança dos EUA.

O passo seguinte tem sido, com financiamento de empresas e milionários locais, interferir nos processos eleitorais, por meio de fundações e agências de ultradireita, que manejam essas redes sociais e juízes, interpelando a luta contra a corrupção, para promover a desestabilização e a queda desses governos. Esses métodos foram utilizados nos últimos sete anos para derrubar governos não alinhados aos EUA no Paraguai, em Honduras, e também no Brasil, na campanha anti-PT, promovendo o impeachment da presidente Dilma Roussef e legitimando na sociedade a condenação e prisão do expresidente Lula.

Outro exemplo importante é o da empresa de big data de informática, a Cambridge Analytica, originalmente com sede na Inglaterra, de propriedade do milionário Steve Bannon. Ela é capaz de mapear o perfil ideológico e pessoal de milhares de usuários no Facebook, para vender para o marketing de grandes empresas e para campanhas políticas. Uma análise mais recente desta empresa pode ser vista no documentário Privacidade hackeada, de 2019, disponível na Internet e no Netflix, realizado pelos 
diretores norte-americanos Karim Amer e Jehane Nouaim. Eles mostram criticamente, com farta documentação, não só os desdobramentos mais recentes da Cambridge Analytica na Inglaterra e seus trabalhos em inúmeros países do mundo, mas também revelam que essa tecnologia de big data constitui na verdade uma verdadeira arma de guerra psicológica. Segundo o filme, esta estratégia opera da seguinte forma:

- ao vasculhar as redes sociais de cada eleitor, com seus likes e dislikes, o software investiga cerca de 5.000 ou mais pontos de informação;

- o software analisa esse conjunto de dados e cria um perfil psicológico e políticoideológico de cada eleitor, capaz de prever seu comportamento político;

- isso permite criar um perfil detalhado de grupos de eleitores, e criar uma propaganda específica ou fake news capazes de sensibilizar cada um dos grupos de eleitores;

- a estratégia visa criar medo e ódio, dividir para reinar, e destruir as bases das instituições democráticas.

O filme ainda lista as atuações mais importantes e recentes da empresa, Além da eleição de Trump nos EUA, tivemos também a de Macri na Argentina, a campanha do Brexit na Inglaterra, e eleições políticas em Gana, Lituânia, Quenia, Romenia, Miamar (na campanha de ódio, expulsão e/ou genocídio de toda uma etnia muçulmana que vivia no país), e em inúmeros outros países.

Estas tecnologias também criam 'bolhas de comunicação' mais estáveis para fins políticos e ideológicos, criando e espalhando fake news via computadores/robôs de repetição, em mensagens para milhões de pessoas nas redes sociais. Hoje, é de conhecimento público que parte significativa das pessoas só se informa por elas, sem acesso ao debate e ao contraditório, gerados mesmo que de forma limitada pela mídia convencional. E sobretudo, faz parte da mesma estratégia também atacar o jornalismo mais sério, particularmente aqueles com um perfil mais investigativo e/ou crítico.

As fake news constituem versões completamente distorcidas sobre eventos correntes, processos históricos, científicos, sociais e políticos, radicalizando ao extremo as estratégias de alguns dos intelectuais neoliberais descritas acima. Elas geralmente visam:

- tentar recontar a história da humanidade e de cada país. Ex.: negar o holocausto; negar o golpe e da ditadura civil-militar no Brasil entre 1964 e 1984;

- desqualificar as ciências, as evidências tecnocientíficas e o debate intelectual. Ex.: difundir a versão criacionista do mundo indicada na Bíblia, ou de que a Terra é plana, ou rejeitar as amplas evidências do aquecimento global provocado pela ação humana;

- desqualificar o debate político e a liberdade de imprensa, bases para a tomada de decisões políticas e para a democracia;

- promover uma estratégia diversionista, como 'cortina de fumaça', para medidas impopulares e problemas graves do governo;

- valorizar o senso comum e a opinião das lideranças políticas carismáticas e de pseudointelectuais. Ex.: Olavo de Carvalho;

- gerar massas com comportamentos fundamentalistas e fascistas; 
- e portanto, solapar as bases racionais da esfera pública e da gestão da questão social, desestabilizar as instituições públicas e democráticas, gerar caos político e enfraquecer a democracia como regime político.

Este último tópico aponta para um fenômeno gravíssimo, pelo qual a guerra psicológica apresenta profundas consequências também epistemológicas e mesmo ontológicas, no sentido de um profundo niilismo3 ${ }^{3}$. Significa que as evidências científicas ou técnicas, e seu debate, na busca de uma melhor aproximação da verdade sobre cada um dos fenômenos naturais, humanos e sociais, passam a ser completamente desprezados, valorizando-se apenas as versões sobre eles. Assim, o poder de persuasão das mídias sociais, com o suporte das poderosas organizações que difundem as fake news e promovem verdadeiras bolhas de comunicação, passam a ter um poder incontrolável de influenciar e manipular amplamente a opinião pública e processos políticos e eleitorais, com um enorme risco de solapar as próprias bases da democracia como regime político. Para exemplificar a importância deste fenômeno no mundo atual, o Oxford Dictionaries, departamento da Universidade de Oxford responsável pela produção de seus dicionários, elegeu em 2016 o termo pós-verdade como a palavra do ano na língua inglesa (FÂBIO, 2016).

A meu ver, o melhor exemplo do uso das estratégias de pós-verdade na esfera política é a atuação da própria empresa Cambridge Analytica e de seu dono, Steve Bannon. Ele criou o grupo internacional The Movement, para se contrapor à Internacional Socialista. O próprio Eduardo Bolsonaro foi escolhido como representante da América Latina, e organizou em dezembro de 2018, em Foz do Iguaçu, a primeira Cúpula Conservadora das Américas (ZANINI, 2019). Uma reportagem mais recente publicada pelo confiável jornal inglês The Guardian (FRESH, 2020), em 4 /o1/20, mostrou que o processo gerado contra a empresa no parlamento inglês acabou estimulando um vazamento de mais de 100 mil de seus documentos internos, revelando uma atuação com manipulações diversas, até aquela data, em 64 países!

E não paramos apenas neste ponto, pois ainda temos as novas tecnologias de deepfakes, nome dado aos vídeos falsos para gerar desinformação. Em seminário ocorrido em meados de outubro de 2019, promovido pela Associação Nacional de Jornais, em São Paulo, foi feito esse alerta para este novo fenômeno preocupante, os deepfakes, ou seja, a capacidade de produção e disseminação de vídeos falsos, produzidos por inteligência artificial a partir de fotos (SEMINÁRIO..., 2019). Segundo as fontes divulgadas no seminário, atualmente $96 \%$ desses vídeos são referentes a imagens sexuais, geralmente de celebridades, sem qualquer consentimento. Além disso, os analistas informam que é quase impossível distinguir os vídeos fakes dos vídeos reais, o que pode levar a uma verdadeira epidemia de falsidades, injúrias e difamações. É possível imaginar as implicações do eventual uso desses vídeos já nas eleições de 2020 e de 2022 em nosso país?

3 Entre os filósofos mais modernos, foi certamente Nietzche o autor mais influente e complexo na defesa do niilismo. Para criticar a cultura ocidental pelo menos a partir de Sócrates, portanto desde a cultura grega clássica, ele afirma que toda a cultura ocidental gerou apenas ilusões, tornando supérflua toda a busca da verdade, e gerando uma existência humana cada vez mais insegura e violenta (BOBBIO et al, 1995, p. 825). 
Além dos efeitos diretamente políticos, é preciso também estar atento aos mecanismos de ação e efeitos subjetivos e psicossociais das novas tecnologias de poder digital e de informação. Para isto, sugiro a leitura da obra Psicopolítica: o neoliberalismo e as novas técnicas de poder, do filósofo coreano Byung-Chul Han, com tradução em português publicada em 2018 (HAN, 2018), contendo uma coletânea de ensaios críticos breves, às vezes polêmicos e unilaterais, mas bastantes sugestivos e provocativos. Han propõe analisar esses processos pela utilização dos conceitos foucaultianos de poder disciplinar e biopolítica, este último entendido como uma forma de poder sobre os corpos. Vejamos algumas indicações ilustrativas deste tipo de análise. Para o autor, o novo sujeito neoliberal do empreendedorismo, como descrito acima, se julga livre de uma coerção externa visível, mas acaba atuando e se explorando de forma até mesmo apaixonada, em uma luta contra si mesmo, com forte suporte da literatura de autoajuda, como um sujeito focado no desempenho e no sucesso de sua própria empresa ou de seu trabalho. E essa nova forma de exploração acaba tomando tudo aquilo que antes era associado apenas à esfera privada e à liberdade, como a emoção, criação, otimização estética (via cirurgias plásticas e academias), o jogo, a autorevelação e autoexposição voluntária, em um ritmo alucinado de comunicação permanente. Os que fracassam, são levados não a questionar o sistema, mas a se culpar. E assim, a depressão e o burn out (esgotamento) se constituem como as formas de sofrimento psíquico mais comuns.

Por outro lado, a condição de cidadão ativo, como fenômeno político complexo, é transformada na condição de consumidor, passivo, que apenas reage como que reclamando da política, da mesma forma que reclama de uma mercadoria com problemas. Em consequência, os políticos e partidos são transformados em fornecedores, que têm que satisfazer seus eleitores como se fossem consumidores ou clientes. Além disso, os sistemas de big data são constituídos como um instrumento político eficiente, tornando possível prognósticos detalhados do comportamento de cada indivíduo. Assim, a própria pessoa é transformada em coisa, pois é quantificável, mensurável e controlável.

Para avançar na analisar na comunicação digital, Han (2018) propõe uma diferenciação entre emoção/afeto, caracterizados pela descarga imediata, e o sentimento, que leva a uma narrativa, se prolongando mais no tempo, com efeitos mais racionalizáveis, e com baixo efeito performativo, ou seja, que não leva a uma ação imediata. Assim, a comunicação digital favorece muito mais a descarga imediata e fugaz da emoção/afeto, deixando-as correrem livres, e é fortemente performativa. Ainda segundo Han (2018), a pressão pela aceleração do fluxo comunicacional acaba gerando uma ditadura da emoção, pré-reflexiva e mais compatível com os apelos imediatos de consumo, com a temporalidade imediata dos games, cuja lógica é entronizada nos processos de trabalho, e com as interpelações dirigidas para a inteligência emocional, que promovem a motivação para o trabalho, tanto em si mesmo, como para os seus eventuais subordinados.

É possível complementar a análise de Han (2018) lembrando de outros aspectos deste processo: a alta velocidade do fluxo atual de mensagens na Internet em tempo real; a supressão nas mensagens escritas das mídias sociais das linguagens corporais, dos elementos denotativos e conotativos, que na comunicação presencial tendem a exercer 
um maior controle das mensagens mais agressivas; as próprias fake news; e o anonimato relativo das mensagens reencaminhadas. Tudo isso colabora para fomentar posicionamentos e julgamentos peremptórios, e fácil depredação moral das pessoas físicas e autoridades nas mídias sociais.

Em minha opinião, as indicações analíticas do coreano Han (2018) são sugestivas e merecem o nosso interesse e discussão.

\section{Novas 'velhas' formas violentas e radicais de gestão de 'populações indesejáveis'}

No atual projeto radical de atuação das políticas neoliberais, além dos processos já indicados acima, estão sendo reatualizadas, em vários países, novas 'velhas' formas violentas de gestão de populações despossuídas ou consideradas 'indesejáveis' pelas elites. Entre estes grupos populacionais, estão os imigrantes, negros, indígenas e outras minorias étnicas; população favelada ou em situação de rua; mulheres; pessoas com deficiência ou com transtorno mental; pessoas com problemas decorrentes do uso de drogas; traficantes de drogas; infratores da lei etc.

Autores como o sociólogo de origem francesa e atuante nos EUA Loïc Wacquant (2001, 2006) já vem denunciando desde a virada da década de 2000 a tendência ao encarceramento em massa dessas populações nos EUA e em diversos países centrais, sendo que na maioria desses países o sistema carcerário é terceirizado, no qual empresas lucram vendendo seus serviços ao Estado. No caso de imigrantes, impõe-se a proibição de entrada, expulsão ou status de ilegalidade/clandestinidade, sem acesso a direitos básicos de cidadania, gerando guetos e novas formas de exploração do trabalho, muitas vezes em situação análoga à escravidão.

Em países periféricos e particularmente latino-americanos, com uma longa história de escravidão, genocídio e, ou extermínio de minorias étnicas, religiosas, de gênero ou identidade sexual, ou de lideranças de movimentos sociais populares (DINIZ; CARINO, 2019), governos recentes de ultradireita estão sendo estimulados pela orientação neoliberal mais radical e pelo lobby da indústria de armas, a implementar medidas de 'necropolítica' (MBAMBE, 2019), ou seja, de gerir esses grupos populacionais, pela segregação radical e extermínio. Nesta perspectiva, a lógica de guerra que existia entre as nações é interiorizada para uma espécie de 'guerra interna' ou 'guerra urbana'. Jeff Halper, um antropólogo israelense, chama esse processo de 'palestinização do mundo', tomando por base as formas e tecnologias com que o complexo militar de segurança israelense lida com a população palestina nos territórios ocupados, e que hoje estão sendo vendidas 'com sucesso' no mundo todo (TELLES, 2019).

Em parte, essa política já está sendo concretizada no Brasil, pelo número de mortos vítimas de policiais. Em 2017, foram 4.222 casos em todo o país, constituindo a polícia que mais mata no mundo. Só no estado do Rio de Janeiro, em 2018 foram 1.534 mortos pela polícia, a maior número desde o início da série em 1998. De janeiro até setembro de 2019, tivemos 1.402 vítimas, que é quase metade de todos os homicídios (3.025) ocorridos no mesmo período (HOMICÍDIOS..., 2019). Ou seja, estamos indo na direção de novos recordes históricos. E as propostas para a área de segurança dos governos de Bolsonaro e Witzel, do Rio de Janeiro, buscam: 
- uma retórica de guerra;

- legalização ampla do porte de armas para civis, incluindo aquelas com maior poder de fogo;

- a possibilidade do abate pela polícia de indivíduos portando armas ilegais;

- e a medida chamada de excludente de ilicitude, que constava do pacote do ministro Sergio Moro para a área de segurança, pela qual policiais podem ser excluídos de criminalização em caso de morte de civis, se o evento ocorrer em função de escusável medo, surpresa ou violenta emoção. O discurso de Bolsonaro para defesa desta proposta incluiu a seguinte frase: "Os caras (os bandidos) vão morrer na rua igual baratas, pô. E tem que ser assim” (MAIA, 2019 apud BOLSONARO, 2019, não paginado).

Essa tendência tem implicações profundas no campo dos direitos humanos, das políticas sociais, da assistência social, da saúde e particularmente da saúde mental e drogas, como também de políticas para deficientes, já que a maioria de nossos usuários de serviços, sem condições de inclusão em condições de igualdade no mercado de trabalho e no sistema educacional, tendem a sofrer formas de exclusão similares aos demais grupos atingidos.

O premiado e elogiado filme brasileiro Bacurau, dirigido por Kleber Mendonça Filho e Juliano Dornelles, e lançado no Brasil em 2019, assumiu essa temática de forma original e crítica, e a meu ver, é imprescindível de ser visto, estando já disponível no Youtube.

\section{Considerações finais}

À primeira vista, as tendências e questões abordadas neste ensaio podem parecer muito distantes da visão ou do campo de atuação do cidadão comum ou do ativista, mais ligados à especificidade de suas áreas de trabalho, como no caso da saúde mental e da luta antimanicomial. No entanto, estas questões podem ditar as perspectivas concretas da vida pessoal e social no mundo e no Brasil, particularmente se esse projeto neoliberal radical tiver condições de ser implementado em toda a sua plenitude. Assim, cabe a nós atuar em duas direções básicas, no curto e médio prazos.

Em primeiro lugar, é preciso desenvolver nossa capacidade de acompanhar e interpretar os 'sinais dos tempos', ou seja, de analisar a conjuntura histórica mais ampla, no sentido de poder ter alguma previsão tanto dos desafios, como também das possíveis contradições, que apontam para brechas e espaços políticos de atuação e resistência. Neste sentido, considero fundamental acompanhar particularmente os seguintes processos históricos que se desdobrarão no curto prazo:

a) As consequências da atual pandemia do corona vírus: na data em que estou finalizando a escrita deste ensaio (17/03/20), já é possível prever que ela provocará uma crise econômica e social mundial gravíssima, de consequências ainda imprevisíveis, que pode por um lado fomentar a xenofobia contra estrangeiros e o fechamento de fronteiras. Porém, do outro lado, pode chamar a atenção para a importância dos laços de reciprocidade social, das políticas sociais, de medidas econômicas anticíclicas contra a recessão, do tipo keynesiano, como os sistemas públicos de saúde, bem como de uma gestão pública baseada em pesquisa científica e em uma imprensa séria e investigativa, 
exatamente na direção contrária do individualismo radical do neoliberalismo e das opiniões e fake news colocadas goela abaixo da sociedade pelo poder das mídias sociais das elites. Essas políticas foram sucateadas ou desmontados em muitos países sob gestão neoliberal radical, deixando-os completamente despreparados para lidar com a pandemia, e agora estão investindo pesado em recursos emergenciais, o que não conseguirá aplacar a gravidade de seus efeitos. Os exemplos mais significativos até agora são o próprio EUA, a Inglaterra, o Brasil e a Itália. Assim, crises sanitárias como essa, apesar de todos os seus dramáticos e trágicos custos humanos, sanitários e sociais, acabam por outro lado criando condições para resistirmos com mais argumentos às tendências mais radicais do neoliberalismo.

b) Os processos políticos e eleitorais em curso em vários países, particularmente nos EUA, Chile e no Brasil: Uma eventual reeleição de Trump nas eleições de 2020 naquele país pode significar manter a legitimidade e a hegemonia mundial deste projeto neoliberal radical, pelo peso geopolítico e econômico dos EUA no mundo. É interessante também acompanhar processos eleitorais nos países com governos de ultradireita. Um bom exemplo disso está na Hungria, onde tivemos recentemente as eleições para a prefeitura de sua capital Budapeste, na qual ganhou uma aliança de centro-esquerda e verdes, de clara oposição ao xenófobo e neonazista governo central. Outro caso significativo a ser acompanhado com carinho é o processo político no Chile, onde uma insurreição popular extremamente forte vem denunciando desde o ano passado as duras mazelas do projeto neoliberal radical implementado desde a década de 1970 pela ditadura Pinochet. Teremos em abril de 2020 um plebiscito para decidir se terão uma Assembleia Constituinte exclusiva ou com metade dos parlamentares já eleitos, e que depois deverá refazer a Constituição promulgada por Pinochet. De forma similar, as eleições municipais deste ano no Brasil nos darão um termômetro mais realista das bases locais que as forças de ultradireita têm no país e sua expressão na esfera política institucional. Além disso, processos eleitorais são uma oportunidade de discutir mais amplamente as plataformas de reivindicações e lutas do movimento antimanicomial, dos demais movimentos sociais populares, bem como de reforçar nossas frentes parlamentares nas câmaras de vereadores e, se possível, chegando a eleger alguns vereadores e prefeitos sintonizados com nossos interesses e lutas.

c) O processo político e econômico em países que passaram por ajustes neoliberais, mas que nos últimos anos têm governos de centro-esquerda, e que estão gradualmente recuperando os direitos econômicos, sociais e políticos da maioria da população: o caso mais significativo aqui é Portugal, governado diretamente pelo Partido Socialista, de centro, mas com o suporte da chamada Geringonça, uma aliança com partidos e movimentos sociais de esquerda. O caso espanhol é mais instável, mas as últimas eleições de 2019 caminharam também na mesma direção. Esses casos apontam para a importância de uma frente política ampla, do tipo antifascista, no enfrentamento do projeto neoliberal radical.

d) No Brasil, os rumos políticos das forças de centro-direita e dos setores militares em relação ao governo Bolsonaro: temos plena consciência de que, no Brasil, o grande capital, os partidos de centro-direita e da grande imprensa apoiam abertamente a política neoliberal de ajustes econômicos e administrativos do governo Bolsonaro. Há 
pelo menos duas razões: eles deixam o governo fazer o jogo sujo das reformas neoliberais sem ter o desgaste direto disso, bem como apoiam a espécie de semi-parlamentarismo atual no Congresso, já que o governo decidiu não investir em uma base parlamentar de apoio, o que gera capital político para suas lideranças, particularmente para Rodrigo Maia. No entanto, o custo e os riscos associados aos desvarios políticos do governo têm sido altos, levando recentemente a um relativo descolamento político, que pode implicar em cisões significativas mais à frente, particularmente nas eleições presidenciais de 2022 . De forma similar, as relações com os setores militares revelam um processo do tipo 'sanfona', de sucessivas aproximações e ataques/distanciamentos. Estas cisões e rachaduras no bloco do poder são significativas, e devem ser acompanhadas com atenção.

e) No Brasil, os rumos das forças de centro-esquerda e esquerda, no sentido de se rearticular com suas bases populares e de superar a fragmentação gerada a partir das eleições de 2018, para formar uma ampla aliança de centro-esquerda e esquerda, similar às frentes antifascistas da história política do século XX: estão abertas as possibilidades não só de atuar em greves e eventos de mobilizações de massa, como tivemos em 2019, como também ir consolidando uma frente que supere a fragmentação política das forças de centro-esquerda e esquerda, tanto na esfera das lutas e articulações na sociedade civil, como também da luta política institucional e dos processos eleitorais. A nossa participação nas eleições municipais de 2020 será um teste dos encaminhamentos nesta direção.

Em segundo lugar, a meu ver, cabe continuar ou retomar, onde possível, nossa militância de base e particularmente micropolítica nos movimentos sociais populares e em nossa atuação como trabalhadores de políticas sociais. Mesmo em conjunturas macropolíticas desfavoráveis, algumas mediações de prefeituras e governos estaduais mais progressistas, como também de ONGs e entidades representativas de profissionais, possibilitam não só manter a resistência, mas também avançar em alguns projetos inovadores, mesmo que em pequena escala. No entanto, eles serão fundamentais para apontar a renovação necessária de nossos projetos e políticas, quando a conjuntura política for mais favorável. Pode ser alentador lembrar que nossa política de reforma psiquiátrica, com serviços tais como os CAPS, que foram difundidos para todo o país, só conseguiu ser implementada por que tivemos duas experiências piloto fundamentais, ainda no final da década de 1980, em condições políticas nacionais muito desfavoráveis, nas cidades de Santos e São Paulo.

Em suma, é preciso reconhecer que a história é sempre dinâmica, contraditória e complexa. Nós, militantes mais antigos, que já atuávamos durante a ditadura, em condições políticas muito mais desfavoráveis que a atual, temos a experiência concreta deste olhar mais alongado para a história, e mostrar aos companheiros das novas gerações que ela está sempre em movimento, e que há sempre esperança. Assim, o que cabe a todos nós é manter sempre acesa essa chama da resistência, mesmo que a fogo baixo ou apenas sob as cinzas, pois, mais à frente, é sempre possível soprar as brasas, colocar mais lenha, e reacender a todo gás nossas labaredas éticas da solidariedade humana e da justiça.

Rio de Janeiro, 17 de março de 2020.

\section{Referências}


ANTÓN, A. Haverá trabalho, mas de má qualidade. São Leopoldo: Instituto Humanitas Unisinos, 17 maio 2019. (Artigo extraído do XIII Congresso Espanhol de Sociologia, Valência (2019), e reproduzido por Rebelión, 16-05-2019. A tradução é do Cepat). Disponível em: http://www.ihu.unisinos.br/78-noticias/589232-haveratrabalho-mas-de-ma-qualidade. Acesso em: $10 \mathrm{fev} .2020$.

BOBBIO, N. et al. Dicionário de política. Brasília (DF): Edit. UnB, 1995. 2 vols.

BROWN, W. Nas ruínas do neoliberalismo: a ascensão da política antidemocrática no Ocidente". São Paulo: Filosófica Polítéia, 2019.

DINIZ, D.; CARINO, G. A necropolítica como regime de governo. El País, 17 jul. 2019. Disponível em: https://brasil.elpais.com/brasil/2019/o7/og/opinion/1562688743 395031.html. Acesso em: 10 fev. 2020.

FÁBIO, André Cabette. O que é 'pós-verdade', a palavra do ano segundo a Universidade de Oxford. Nexo, 16 nov. 2016. Disponível em: https://www.nexojornal.com.br/expresso/2016/11/16/O-que-\%C3\%A9\%Е2 $\% 80 \% 98 \mathrm{p} \% \mathrm{C}_{3} \% \mathrm{~B} 3$ s-verdade $\% \mathrm{E}_{2} \% 80 \% 99$-a-palavra-do-ano-segundo-aUniversidade-de-Oxford. Acesso em: 8 fev. 2020.

FRESH Cambridge Analytica leak 'shows global manipulation is out of control'. The Gardian, London, 4 jan. 2020. Disponível em: https://www.theguardian.com/uknews/2020/jan/o4/cambridge-analytica-data-leak-global-election-manipulation. Acesso em: 8 fev. 2020.

HAN, B-C. Psicopolítica: o neoliberalismo e as novas técnicas de poder. Belo Horizonte: Âyiné, 2018.

HOMICÍDIOS caem 22,5\% e mortes envolvendo policiais sobem $16 \%$ no RJ, diz ISP. G1 RIO, 19 set. 2019. Disponível em: https:/g1.globo.com/rj/rio-dejaneiro/noticia/2019/o9/19/homicidios-caem-215percent-e-mortes-envolvendopoliciais-sobem-16percent-no-rj.ghtml. Acesso em: 9 fev. 2020.

LAGO, K.; CODO, W. Fadiga por compaixão: o sofrimento dos profissionais de saúde. Petrópolis: Vozes, 2010.

MAIA, G. "Os caras vão morrer na rua igual barata, pô", diz Bolsonaro sobre criminosos. O Globo, 5 ago. 2019. Disponível em: https://oglobo.globo.com/brasil/oscaras-vao-morrer-na-rua-igual-barata-po-diz-bolsonaro-sobre-criminosos-23855554. Acesso em: 9 fev. 2020.

MBEMBE, A. Necropolítica. São Paulo: Ed, N-1, 2019. 
SELIGMANN-SILVA, E. Trabalho e desgaste mental do trabalho. São Paulo: Cortez, 2011.

SEMINÁRIO da ANJ debate a disseminação na rede dos 'deepfakes'. O Globo, São Paulo, 17 out. 2019. Disponível em: https://oglobo.globo.com/brasil/seminario-da-anj-debatedisseminacao-na-rede-dos-deepfakes-24025429. Acesso em: 7 fev. 2020.

TELLES, V. A violência como forma de governo. LE MONDE DIPLOMATIQUE BRASIL, 31 jan. 2019. Disponível em: https://diplomatique.org.br/a-violencia-comoforma-de-governo/. Acesso em: 9 fev. 2020.

VASCONCELOS, E. M. Reforma psiquiátrica, tempos sombrios e resistência: diálogos com o marxismo e o serviço social. São Paulo: Tempo Social, 2016.

VASCONCELOS, E. M. Karl Marx e a subjetividade humana. São Paulo: Hucitec, 2010. 3 vols.

VASCONCELOS, E. M.; CAVALCANTE, R. Religiões e o paradoxo apoio social: intolerância, e implicações na política de drogas e comunidades terapêuticas. São Paulo: Hucitec, 2019.

WACQUANT, L. A miséria governada através do sistema penal. Rio de Janeiro: Revan, 2006.

WACQUANT, L. As prisões da miséria. Rio de Janeiro: Jorge Zahar, 2001.

WEISSHEIMER, M. "Sociedade que deu origem ao PT não existe mais. Estamos com uma retórica envelhecida”. Constata, Márcio Pochmann. Sul21, Porto Alegre, 13 ago. 2019. São Leopoldo: Instituto Humanitas Unisinos, 15 ago. 2019. Disponível em: http://www.ihu.unisinos.br/78-noticias/591700-pochmann-sociedade-que-deu-origemao-pt-nao-existe-mais-estamos-com-um-retorica-envelhecida.Acesso em: 8 fev. 2020

ZANINI, F. Aliados de Bolsonaro sofrem derrotas, sonho Internacional Destra fraqueja. Saída pela Direita, São Paulo, 6 out. 2019. Reportagem disponível em: https://saidapeladireita.blogfolha.uol.com.br/2019/10/o6/aliados-de-bolsonaro-sofremderrotas-e-sonho-de-internacional-destra-fraqueja/. Acesso em: 8 fev. 2020. 